\title{
Kamenev and Philos-types oscillation criteria for fourth-order neutral differential equations
}

\section{Omar Bazighifan ${ }^{1 *}$ (D)}

\section{"Correspondence:}

o.bazighifan@gmail.com

'Department of Mathematics,

Faculty of Science, Hadhramout

University, Hadhramout, Yemen

\section{Springer}

\begin{abstract}
This work is concerned with the oscillatory behavior of solutions of fourth-order neutral differential equations. By using the Riccati transformation and integral averaging techniques we obtain some new Kamenev-type and Philos-type oscillation criteria. Our results extend and improve some known results in the literature. An example is given to illustrate our main results.
\end{abstract}

MSC: $34 \mathrm{C} 10 ; 34 \mathrm{~K} 11$

Keywords: Fourth-order neutral differential equations; Oscillatory solutions

\section{Introduction}

In this paper, we establish some oscillation criteria for the fourth-order neutral differential equation of the form

$$
L_{y}^{\prime}+q(t) y^{\beta}(\delta(t))=0, \quad t \geq t_{0},
$$

where $L_{y}=r(t)\left(z^{\prime \prime \prime}(t)\right)^{\gamma}$ and $z(t):=y(t)+p(t) y(\tau(t))$. We suppose that:

$\left(S_{1}\right) \gamma$ and $\beta$ are quotients of odd positive integers,

$\left(S_{2}\right) r, p, q \in C\left[t_{0}, \infty\right), r(t)>0, r^{\prime}(t) \geq 0, q(t)>0,0 \leq p(t)<p_{0}<1, \tau, \delta \in C\left[t_{0}, \infty\right), \tau(t) \leq$ $t, \lim _{t \rightarrow \infty} \tau(t)=\lim _{t \rightarrow \infty} \delta(t)=\infty$. and

$$
\int_{t_{0}}^{\infty} \frac{1}{r^{1 / \gamma}(s)} \mathrm{d} s=\infty
$$

By a solution of (1) we mean a function $y \in C^{3}\left[t_{y}, \infty\right), t_{y} \geq t_{0}$, satisfying (1) on $\left[t_{y}, \infty\right)$ and such that $r(t)\left(z^{\prime \prime \prime}(t)\right)^{\gamma} \in C^{1}\left[t_{y}, \infty\right)$. We consider only those solutions $y$ of (1) that satisfy $\sup \{|y(t)|: t \geq T\}>0$ for all $T \geq t_{y}$.

A solution $y$ of (1) is said to be nonoscillatory if it is ultimately positive or negative; otherwise, it is said to be oscillatory. The equation itself is called oscillatory if all its solutions are oscillatory.

Delay differential equations play an important role in applications of real-world life. One area of active research in recent years is studying the sufficient conditions for oscillation of delay differential equations, see [1-23] and the references therein.

(c) The Author(s) 2020. This article is licensed under a Creative Commons Attribution 4.0 International License, which permits use, sharing, adaptation, distribution and reproduction in any medium or format, as long as you give appropriate credit to the original author(s) and the source, provide a link to the Creative Commons licence, and indicate if changes were made. The images or other third party material in this article are included in the article's Creative Commons licence, unless indicated otherwise in a credit line to the material. If material is not included in the article's Creative Commons licence and your intended use is not permitted by statutory regulation or exceeds the permitted use, you will need to obtain permission directly from the copyright holder. To view a copy of this licence, visit http://creativecommons.org/licenses/by/4.0/. 
In particular, the Emden-Fowler delay differential equations have numerous applications in mathematical, theoretical, and chemical physics; see, for instance, [24-27].

Let us briefly comment on a number of related results, which motivated our study. The authors in $[28,29]$ were concerned with oscillatory behavior of solutions of fourth-order neutral differential equations and established some new oscillation criteria.

In $[30,31]$ the authors considered the equation

$$
(y(t)+p(t) y(\tau(t)))^{(n)}+q(t) f(y(\delta(t)))=0
$$

and established the criteria for the solutions to be oscillatory when $0 \leq p(t)<1$.

Xing et al. [32] proved that the equation

$$
\left(r(t)\left((y(t)+p(t) y(\tau(t)))^{(n-1)}\right)^{\gamma}\right)^{\prime}+q(t) y^{\gamma}(\delta(t))=0
$$

is oscillatory if

$$
\left(\delta^{-1}(t)\right)^{\prime} \geq \delta_{0}>0, \quad \tau^{\prime}(t) \geq \tau_{0}>0, \quad \tau^{-1}(\delta(t))<t,
$$

and

$$
\liminf _{t \rightarrow \infty} \int_{\tau^{-1}(\delta(t))}^{t} \frac{\widehat{q}(s)}{r(s)}\left(s^{n-1}\right)^{\gamma} \mathrm{d} s>\left(\frac{1}{\delta_{0}}+\frac{p_{0}^{\gamma}}{\delta_{0} \tau_{0}}\right) \frac{((n-1) !)^{\gamma}}{\mathrm{e}}
$$

where $n$ is even, and $\widehat{q}(t):=\min \left\{q\left(\delta^{-1}(t)\right), q\left(\delta^{-1}(\tau(t))\right)\right\}$.

Moaaz et al. [33] proved that if there exist positive functions $\eta, \zeta \in C^{1}\left(\left[t_{0}, \infty\right), R\right)$ such that the equations

$$
\psi^{\prime}(t)+\left(\frac{\mu\left(\tau^{-1}(\eta(t))\right)^{n-1}}{(n-1) ! r^{1 / \gamma}\left(\tau^{-1}(\eta(t))\right)}\right)^{\gamma} q(t) P_{n}^{\gamma}(\delta(t)) \psi\left(\tau^{-1}(\eta(t))\right)=0
$$

and

$$
\phi^{\prime}(t)+\tau^{-1}(\zeta(t)) R_{n-3}(t) \phi\left(\tau^{-1}(\zeta(t))\right)=0
$$

are oscillatory, where

$$
\begin{aligned}
& P_{n}(t)=\frac{1}{p\left(\tau^{-1}(t)\right)}\left(1-\frac{\left(\tau^{-1}\left(\tau^{-1}(t)\right)\right)^{n-1}}{\left(\tau^{-1}(t)\right)^{n-1} p\left(\tau^{-1}\left(\tau^{-1}(t)\right)\right)}\right), \\
& R_{n-3}(t)=\int_{t}^{\infty} R_{n-4}(s) \mathrm{d} s,
\end{aligned}
$$

and

$$
R_{0}(t)=\left(\frac{1}{r(t)} \int_{t}^{\infty} q(s) P_{2}^{\gamma}(\sigma(s)) \mathrm{d} s\right)^{1 / \gamma}
$$

then (1) is oscillatory. 
Our aim in the present paper is employing the Riccati technique to establish some new Kamenev-type and Philos-type conditions for the oscillation of all solutions of equation (1) under condition (2).

The paper is organized as follows. In Sect. 2, we give four lemmas to prove the main results. In Sect. 3, we establish new oscillation results for (1) by using Riccati transformation. In Sect. 4, we establish some new Kamenev-type oscillation criteria for (1). In Sect. 5, we use the integral averaging technique to establish some new Philos-type conditions for the oscillation of all solutions of equation (1). Finally, we present an example and some conclusions to illustrate the main results.

Remark 1.1 All functional inequalities considered in this paper are assumed to hold eventually, that is, they are satisfied for all $t$ large enough.

Remark 1.2 Without loss of generality, we can deal only with the positive solutions of (1).

Notation For convenience, we use the following notation:

$$
\begin{aligned}
& A_{1}(t)=q(t)\left(1-p_{0}\right)^{\beta} M^{\beta-\gamma}(\delta(t)), \\
& A_{2}(t)=\gamma \varepsilon \frac{\delta^{2}(t) \zeta \delta^{\prime}(t)}{r^{1 / \gamma}(t)}, \\
& \tilde{A}_{1}(t)=\int_{t}^{\infty} A_{1}(s) \mathrm{d} s, \quad B_{1}(t)=\frac{\pi^{\prime}(t)}{\pi(t)}, \\
& B_{2}(t)=\pi(t) q(t)\left(1-p_{0}\right)^{\beta} M^{\beta-\gamma}(\delta(t)),
\end{aligned}
$$

and

$$
B_{3}(t)=\gamma \varepsilon \frac{\delta^{2}(t) \zeta \delta^{\prime}(t)}{(\pi(t) r(t))^{1 / \gamma}} .
$$

\section{Some auxiliary lemmas}

We will employ the following lemmas:

Lemma 2.1 ([34], Lemma 2.1) Let $\gamma \geq 1$ be the ratio of two odd numbers, and let $V>0$ and $U$ be constants. Then

$$
U y-V y^{(\gamma+1) / \gamma} \leq \frac{\gamma^{\gamma}}{(\gamma+1)^{\gamma+1}} \frac{U^{\gamma+1}}{V^{\gamma}} .
$$

Lemma 2.2 ([1, Lemma 2.2.3]) Let $y \in C^{n}\left(\left[t_{0}, \infty\right),(0, \infty)\right)$. Assume that $y^{(n)}(t)$ is of fixed sign and not identically zero on $\left[t_{0}, \infty\right)$ and that there exists $t_{1} \geq t_{0}$ such that $y^{(n-1)}(t) y^{(n)}(t) \leq 0$ for all $t \geq t_{1}$. If $\lim _{t \rightarrow \infty} y(t) \neq 0$, then for every $\mu \in(0,1)$, there exists $t_{\mu} \geq t_{1}$ such that

$$
y(t) \geq \frac{\mu}{(n-1) !} t^{n-1}\left|y^{(n-1)}(t)\right| \quad \text { for } t \geq t_{\mu} .
$$

Lemma 2.3 ([35]) Let $y(t)$ be a positive and n-times differentiable function on an interval $[T, \infty)$ with its nth derivative $y^{(n)}(t)$ nonpositive on $[T, \infty)$, not identically zero on any interval of the form $\left[T^{\prime}, \infty\right), T^{\prime} \geq T$, and such that $y^{(n-1)}(t) y^{(n)}(t) \leq 0, t \geq t_{y}$. Then there exist 
constants $0<\theta<1$ and $N>0$ such that

$$
y^{\prime}(\theta t) \geq N t^{n-2} y^{(n-1)}(t)
$$

for all sufficient larget.

Lemma 2.4 Assume that $y$ is an eventually positive solution of (1). Then

$$
\left(r(t)\left(z^{\prime \prime \prime}(t)\right)^{\gamma}\right)^{\prime} \leq-q(t)\left(1-p_{0}\right)^{\beta} z^{\beta}(\delta(t)) .
$$

Proof Let $y$ be an eventually positive solution of (1). Then there exists $t_{1} \geq t_{0}$ such that $y(t)>0, y(\tau(t))>0$ and $y(\delta(t))>0$ for $t \geq t_{1}$. Since $r^{\prime}(t)>0$, we have

$$
z(t)>0, \quad z^{\prime}(t)>0, \quad z^{\prime \prime \prime}(t)>0, \quad z^{(4)}(t)<0, \quad\left(r(t)\left(z^{\prime \prime \prime}(t)\right)^{\gamma}\right)^{\prime} \leq 0
$$

for $t \geq t_{1}$. From the definition of $z$ we get

$$
\begin{aligned}
y(t) & \geq z(t)-p_{0} y(\tau(t)) \geq z(t)-p_{0} z(\tau(t)) \\
& \geq\left(1-p_{0}\right) z(t),
\end{aligned}
$$

which, together with (1), gives

$$
\left(r(t)\left(z^{\prime \prime \prime}(t)\right)^{\gamma}\right)^{\prime}+q(t)\left(1-p_{0}\right)^{\beta} z^{\beta}(\delta(t)) \leq 0
$$

The proof is complete.

\section{Oscillation criteria}

In this section, we establish new oscillation results for (1) by using the Riccati transformation.

Lemma 3.1 Let y be an eventually positive solution of $(1)$. If there exist constants $\varepsilon \in(0,1)$ and $\zeta>0$ such that

$$
\varphi(t):=\frac{r(t)\left(z^{\prime \prime \prime}(t)\right)^{\gamma}}{z^{\gamma}(\zeta \delta(t))}
$$

then

$$
\varphi^{\prime}(t)+A_{1}(t)+A_{2}(t) \varphi^{(\gamma+1) / \gamma}(t) \leq 0
$$

Proof Let $y$ be an eventually positive solution of (1). Using Lemma 2.4, we obtain that (14) holds. From (17) we see that $\varphi(t)>0$ for $t \geq t_{1}$, and using (14), we obtain

$$
\varphi^{\prime}(t) \leq \frac{-q(t)\left(1-p_{0}\right)^{\beta} z^{\beta}(\delta(t)) .}{z^{\gamma}(\zeta \delta(t))}-\gamma \frac{r(t)\left(z^{\prime \prime \prime}(t)\right)^{\gamma} z^{\prime}(\zeta \delta(t)) \zeta \delta^{\prime}(t)}{z^{\gamma+1}(\zeta \delta(t))}
$$

From Lemma 2.3 we have

$$
\varphi^{\prime}(t) \leq-q(t)\left(1-p_{0}\right)^{\beta} z^{\beta-\gamma}(\delta(t))-\gamma \frac{r(t)\left(z^{\prime \prime \prime}(t)\right)^{\gamma} \varepsilon \delta^{2}(t) z^{\prime \prime \prime}(\delta(t)) \zeta \delta^{\prime}(t)}{z^{\gamma+1}(\zeta \delta(t))}
$$


which is

$$
\varphi^{\prime}(t) \leq-q(t)\left(1-p_{0}\right)^{\beta} z^{\beta-\gamma}(\delta(t))-\gamma \varepsilon \frac{r(t) \delta^{2}(t) \zeta \delta^{\prime}(t)\left(z^{\prime \prime \prime}(t)\right)^{\gamma+1}}{z^{\gamma+1}(\zeta \delta(t))} .
$$

Using (17) we have

$$
\varphi^{\prime}(t) \leq-q(t)\left(1-p_{0}\right)^{\beta} z^{\beta-\gamma}(\delta(t))-\gamma \varepsilon \frac{\delta^{2}(t) \zeta \delta^{\prime}(t)}{r^{1 / \gamma}(t)} \varphi^{(\gamma+1) / \gamma}(t) .
$$

Since $z^{\prime}(t)>0$, there exist $t_{2} \geq t_{1}$ and a constant $M>0$ such that

$$
z(t)>M .
$$

Then (22) turns into

$$
\varphi^{\prime}(t) \leq-q(t)\left(1-p_{0}\right)^{\beta} M^{\beta-\gamma}(\delta(t))-\gamma \varepsilon \frac{\delta^{2}(t) \zeta \delta^{\prime}(t)}{r^{1 / \gamma}(t)} \varphi^{(\gamma+1) / \gamma}(t),
$$

that is,

$$
\varphi^{\prime}(t)+A_{1}(t)+A_{2}(t) \varphi^{(\gamma+1) / \gamma}(t) \leq 0 .
$$

The proof is complete.

Theorem 3.1 Assume that (2) holds. If

$$
\liminf _{t \rightarrow \infty} \frac{1}{\tilde{A}_{1}(t)} \int_{t}^{\infty} A_{2}(s) \tilde{A}_{1}^{\frac{\gamma+1}{\gamma}}(s) \mathrm{d} s>\frac{\gamma}{(\gamma+1)^{\frac{\gamma+1}{\gamma}}}
$$

then (1) is oscillatory.

Proof Let $y$ be an eventually positive solution of (1). Then there exists $t_{1} \geq t_{0}$ such that $y(t)>0, y(\tau(t))>0$, and $y(\delta(t))>0$ for $t \geq t_{1}$. By Lemma 3.1 we get that (18) holds.

Integrating (18) from $t$ to $l$, we get

$$
\varphi(l)-\varphi(t)+\int_{t}^{l} A_{1}(s) \mathrm{d} s+\int_{t}^{l} A_{2}(s) \varphi^{\frac{\gamma+1}{\gamma}}(s) \mathrm{d} s \leq 0 .
$$

Letting $l \rightarrow \infty$ and using $\varphi>0$ and $\varphi^{\prime}<0$, we have

$$
\varphi(t) \geq \tilde{A}_{1}(t)+\int_{t}^{\infty} A_{2}(s) \varphi^{\frac{\gamma+1}{\gamma}}(s) \mathrm{d} s .
$$

This implies

$$
\frac{\varphi(t)}{\tilde{A}_{1}(t)} \geq 1+\frac{1}{\tilde{A}_{1}(t)} \int_{t}^{\infty} A_{2}(s) \tilde{A}_{1}^{\frac{\gamma+1}{\gamma}}(s)\left(\frac{\varphi(s)}{\tilde{A}_{1}(s)}\right)^{\frac{\gamma+1}{\gamma}} \mathrm{d} s .
$$


Let $\lambda=\inf _{t \geq T} \varphi(t) / \tilde{A}_{1}(t)$. Then obviously $\lambda \geq 1$. Thus from (26) and (29) we see that

$$
\lambda \geq 1+\gamma\left(\frac{\lambda}{\gamma+1}\right)^{(\gamma+1) / \gamma}
$$

or

$$
\frac{\lambda}{\gamma+1} \geq \frac{1}{\gamma+1}+\frac{\gamma}{\gamma+1}\left(\frac{\lambda}{\gamma+1}\right)^{(\gamma+1) / \gamma},
$$

which contradicts the admissible values of $\lambda \geq 1$ and $\gamma>0$. Therefore the proof is complete.

\section{Kamenev-type criteria}

In this section, we establish new Kamenev-type oscillation criteria for (1).

Lemma 4.1 Let y be an eventually positive solution of (1), and suppose that (15) holds. If there exist a function $\pi \in C^{1}\left(\left[t_{0}, \infty\right), R^{+}\right)$and constants $\varepsilon \in(0,1)$ and $\zeta>0$ such that

$$
\varpi(t):=\pi(t) \frac{r(t)\left(z^{\prime \prime \prime}(t)\right)^{\gamma}}{z^{\gamma}(\zeta \delta(t))}
$$

then

$$
\varpi^{\prime}(t)-B_{1}(t) \varpi(t)+B_{2}(t)+B_{3}(t) \varpi^{(\gamma+1) / \gamma}(t) \leq 0 .
$$

Proof Let $y$ be an eventually positive solution of (1). Using Lemma 2.4, we obtain that (14) holds. From (32) we see that $\varpi(t)>0$ for $t \geq t_{1}$, and using (14), we obtain

$$
\begin{aligned}
\varpi^{\prime}(t) \leq & \pi^{\prime}(t) \frac{r(t)\left(z^{\prime \prime \prime}(t)\right)^{\gamma}}{z^{\gamma}(\zeta \delta(t))}+\pi(t) \frac{-q(t)\left(1-p_{0}\right)^{\beta} z^{\beta}(\delta(t))}{z^{\gamma}(\zeta \delta(t))} \\
& -\gamma \pi(t) \frac{r(t)\left(z^{\prime \prime \prime}(t)\right)^{\gamma} z^{\prime}(\zeta \delta(t)) \zeta \delta^{\prime}(t)}{z^{\gamma+1}(\zeta \delta(t))} .
\end{aligned}
$$

From Lemma 2.3 we have

$$
\begin{aligned}
\varpi^{\prime}(t) \leq & \pi^{\prime}(t) \frac{r(t)\left(z^{\prime \prime \prime}(t)\right)^{\gamma}}{z^{\gamma}(\zeta \delta(t))}-\pi(t) q(t)\left(1-p_{0}\right)^{\beta} z^{\beta-\gamma}(\delta(t)) \\
& -\gamma \pi(t) \frac{r(t)\left(z^{\prime \prime \prime}(t)\right)^{\gamma} \varepsilon \delta^{2}(t) z^{\prime \prime \prime}(\delta(t)) \zeta \delta^{\prime}(t)}{z^{\gamma+1}(\zeta \delta(t))},
\end{aligned}
$$

which is

$$
\begin{aligned}
\varpi^{\prime}(t) \leq & \pi^{\prime}(t) \frac{r(t)\left(z^{\prime \prime \prime}(t)\right)^{\gamma}}{z^{\gamma}(\zeta \delta(t))}-\pi(t) q(t)\left(1-p_{0}\right)^{\beta} z^{\beta-\gamma}(\delta(t)) \\
& -\gamma \varepsilon \pi(t) \frac{r(t) \delta^{2}(t) \zeta \delta^{\prime}(t)\left(z^{\prime \prime \prime}(t)\right)^{\gamma+1}}{z^{\gamma+1}(\zeta \delta(t))} .
\end{aligned}
$$


By (32) we have

$$
\begin{aligned}
\varpi^{\prime}(t) \leq & \frac{\pi^{\prime}(t)}{\pi(t)} \varpi(t)-\pi(t) q(t)\left(1-p_{0}\right)^{\beta} z^{\beta-\gamma}(\delta(t)) \\
& -\gamma \varepsilon \frac{\delta^{2}(t) \zeta \delta^{\prime}(t)}{(\pi(t) r(t))^{1 / \gamma}} \varpi^{(\gamma+1) / \gamma}(t) .
\end{aligned}
$$

Since $z^{\prime}(t)>0$, there exist $t_{2} \geq t_{1}$ and $M>0$ such that

$$
z(t)>M \text {. }
$$

Hence we obtain

$$
\begin{aligned}
\varpi^{\prime}(t) \leq & \frac{\pi^{\prime}(t)}{\pi(t)} \varpi(t)-\pi(t) q(t)\left(1-p_{0}\right)^{\beta} M^{\beta-\gamma}(\delta(t)) \\
& -\gamma \varepsilon \frac{\delta^{2}(t) \zeta \delta^{\prime}(t)}{(\pi(t) r(t))^{1 / \gamma}} \varpi^{(\gamma+1) / \gamma}(t),
\end{aligned}
$$

that is

$$
\varpi^{\prime}(t)-B_{1}(t) \varpi(t)+B_{2}(t)+B_{3}(t) \varpi^{(\gamma+1) / \gamma}(t) \leq 0 .
$$

The proof is complete.

Theorem 4.1 Assume that (2) holds. If there exist a function $\pi \in C^{1}\left(\left[t_{0}, \infty\right), R^{+}\right)$such that

$$
\limsup _{t \rightarrow \infty} \frac{1}{t^{n}} \int_{t_{0}}^{t}(t-s)^{n}\left(B_{2}(t)-\frac{r(s)}{(\gamma+1)^{\gamma+1}} \frac{\left(\pi^{\prime}(s)\right)^{\gamma+1}}{\left(\varepsilon \pi(s) \delta^{2}(t) \zeta \delta^{\prime}(s)\right)^{\gamma}}\right) \mathrm{d} s=\infty
$$

then (1) is oscillatory.

Proof Let $y$ be a nonoscillatory solution of $(1)$ on $\left[t_{0}, \infty\right)$. Without loss of generality, we can assume that $u$ is eventually positive. Using Lemma 4.1, we get that (33) holds. From Lemma 2.1 we set

$$
U=\pi^{\prime} / \pi, \quad V=\gamma \varepsilon \delta^{2}(t) \zeta \delta^{\prime}(t) /(\pi(t) r(t))^{1 / \gamma} \quad \text { and } \quad y=\varpi(t) .
$$

Thus we have

$$
\varpi^{\prime}(t) \leq-B_{2}(t)+\frac{r(t)}{(\gamma+1)^{\gamma+1}} \frac{\left(\pi^{\prime}(t)\right)^{\gamma+1}}{\left(\varepsilon \pi(t) \delta^{2}(t) \zeta \delta^{\prime}(t)\right)^{\gamma}}
$$

and

$$
-\int_{t_{0}}^{t}(t-s)^{n} \varpi^{\prime}(s) \mathrm{d} s \geq \int_{t_{0}}^{t}(t-s)^{n}\left(B_{2}(t)-\frac{r(s)}{(\gamma+1)^{\gamma+1}} \frac{\left(\pi^{\prime}(s)\right)^{\gamma+1}}{\left(\varepsilon \pi(s) \delta^{2}(t) \zeta \delta^{\prime}(s)\right)^{\gamma}}\right) \mathrm{d} s .
$$


Since

$$
\int_{t_{0}}^{t}(t-s)^{n} \varpi^{\prime}(s) \mathrm{d} s=n \int_{t_{0}}^{t}(t-s)^{n-1} \varphi(s) \mathrm{d} s-\left(t-t_{0}\right)^{n} \varpi\left(t_{0}\right)
$$

we get

$$
\begin{aligned}
& \left(\frac{t-t_{0}}{t}\right)^{n} \varpi^{\prime}\left(t_{0}\right)-\frac{n}{t^{n}} \int_{t_{0}}^{t}(t-s)^{n-1} \varpi(s) \mathrm{d} s \\
& \quad \geq \frac{1}{t^{n}} \int_{t_{0}}^{t}(t-s)^{n}\left(B_{2}(t)-\frac{r(s)}{(\gamma+1)^{\gamma+1}} \frac{\left(\pi^{\prime}(s)\right)^{\gamma+1}}{\left(\varepsilon \pi(s) \delta^{2}(t) \zeta \delta^{\prime}(s)\right)^{\gamma}}\right) \mathrm{d} s .
\end{aligned}
$$

Hence

$$
\frac{1}{t^{n}} \int_{t_{0}}^{t}(t-s)^{n}\left(B_{2}(t)-\frac{r(s)}{(\gamma+1)^{\gamma+1}} \frac{\left(\pi^{\prime}(s)\right)^{\gamma+1}}{\left(\varepsilon \pi(s) \delta^{2}(t) \zeta \delta^{\prime}(s)\right)^{\gamma}}\right) \mathrm{d} s \leq\left(\frac{t-t_{0}}{t}\right)^{n} \varpi\left(t_{0}\right),
$$

and so

$$
\limsup _{t \rightarrow \infty} \frac{1}{t^{n}} \int_{t_{0}}^{t}(t-s)^{n}\left(B_{2}(t)-\frac{r(s)}{(\gamma+1)^{\gamma+1}} \frac{\left(\pi^{\prime}(s)\right)^{\gamma+1}}{\left(\varepsilon \pi(s) \delta^{2}(t) \zeta \delta^{\prime}(s)\right)^{\gamma}}\right) \mathrm{d} s \rightarrow \varpi\left(t_{0}\right),
$$

which contradicts (36), and this completes the proof.

\section{Philos-type oscillation result}

In the section, we employ the integral averaging technique to establish a Philos-type oscillation criterion for (1).

Definition Let

$$
D=\left\{(t, s) \in R^{2}: t \geq s \geq t_{0}\right\} \quad \text { and } \quad D_{0}=\left\{(t, s) \in R^{2}: t>s \geq t_{0}\right\} .
$$

A kernel function $H \in C(D, R)$ is said to belong to the function class $\mathfrak{\Im}$, written as $H \in \mathfrak{I}$, if

(i) $H(t, s)=0$ for $t \geq t_{0}, H(t, s)>0,(t, s) \in D_{0}$;

(ii) $H(t, s)$ has a continuous and nonpositive partial derivative $\partial H / \partial s$ on $D_{0}$, and there exist functions $\pi \in C^{1}\left(\left[t_{0}, \infty\right),(0, \infty)\right)$ and $h \in C\left(D_{0}, R\right)$ such that

$$
\frac{\partial}{\partial s} H(t, s)+\frac{\pi^{\prime}(s)}{\pi(s)} H(t, s)=h(t, s) H^{\gamma /(\gamma+1)}(t, s) .
$$

Theorem 5.1 Assume that (2) holds. If there exist a positive function $\pi \in C^{1}\left(\left[t_{0}, \infty\right), R\right)$ such that

$$
\limsup _{t \rightarrow \infty} \frac{1}{H\left(t, t_{1}\right)} \int_{t_{1}}^{t}\left(H(t, s) B_{2}(s)-\frac{h^{\gamma+1}(t, s)}{(\gamma+1)^{\gamma+1}} \frac{\pi(s) r(t)}{\left(\gamma \varepsilon \delta^{2}(s) \zeta \delta^{\prime}(s)\right)^{\gamma}}\right) \mathrm{d} s=\infty
$$

then (1) is oscillatory. 
Proof Let $y$ is a nonoscillatory solution of $(1)$ on $\left[t_{0}, \infty\right)$. Without loss of generality, we can assume that $u$ is eventually positive. From Lemma 4.1 we get that (33) holds. Multiplying (33) by $H(t, s)$ and integrating the resulting inequality from $t_{1}$ to $t$, we find that

$$
\begin{aligned}
\int_{t_{1}}^{t} H(t, s) B_{2}(s) \mathrm{d} s \leq & \varpi\left(t_{1}\right) H\left(t, t_{1}\right)+\int_{t_{1}}^{t}\left(\frac{\partial}{\partial s} H(t, s)+B_{1}(s) H(t, s)\right) \varpi(s) \mathrm{d} s \\
& -\int_{t_{1}}^{t} B_{3}(s) H(t, s) \varpi^{\frac{\gamma+1}{\gamma}}(s) \mathrm{d} s .
\end{aligned}
$$

From (44) we get

$$
\begin{aligned}
\int_{t_{1}}^{t} H(t, s) B_{2}(s) \mathrm{d} s \leq & \varpi\left(t_{1}\right) H\left(t, t_{1}\right)+\int_{t_{1}}^{t} h(t, s) H^{\gamma /(\gamma+1)}(t, s) \varpi(s) \mathrm{d} s \\
& -\int_{t_{1}}^{t} B_{3}(s) H(t, s) \varpi^{\frac{\gamma+1}{\gamma}}(s) \mathrm{d} s .
\end{aligned}
$$

Using Lemma 2.1 with $V=B_{3}(s) H(t, s), U=h(t, s) H^{\gamma /(\gamma+1)}(t, s)$, and $y=\varpi(s)$, we get

$$
\begin{aligned}
& h(t, s) H^{\gamma /(\gamma+1)}(t, s) \varpi(s)-B_{3}(s) H(t, s) \varpi^{\frac{\gamma+1}{\gamma}}(s) \\
& \quad \leq \frac{h^{\gamma+1}(t, s)}{(\gamma+1)^{\gamma+1}} \frac{\pi(s) r(t)}{\left(\gamma \varepsilon \delta^{2}(s) \zeta \delta^{\prime}(s)\right)^{\gamma}}
\end{aligned}
$$

which implies that

$$
\frac{1}{H\left(t, t_{1}\right)} \int_{t_{1}}^{t}\left(H(t, s) B_{2}(s)-\frac{h^{\gamma+1}(t, s)}{(\gamma+1)^{\gamma+1}} \frac{\pi(s) r(t)}{\left(\gamma \varepsilon \delta^{2}(s) \zeta \delta^{\prime}(s)\right)^{\gamma}}\right) \mathrm{d} s \leq \varpi\left(t_{1}\right),
$$

a contradiction to (45).

Theorem 5.1 is proved.

Corollary 5.1 If condition (45) in Theorem 5.1 is replaced by the conditions

$$
\limsup _{t \rightarrow \infty} \frac{1}{H\left(t, t_{1}\right)} \int_{t_{1}}^{t} H(t, s) B_{2}(s) \mathrm{d} s=\infty
$$

and

$$
\limsup _{t \rightarrow \infty} \frac{1}{H\left(t, t_{1}\right)} \int_{t_{1}}^{t} \frac{h^{\gamma+1}(t, s)}{(\gamma+1)^{\gamma+1}} \frac{\pi(s) r(t)}{\left(\gamma \varepsilon \delta^{2}(s) \zeta \delta^{\prime}(s)\right)^{\gamma}} \mathrm{d} s<\infty
$$

then (1) is oscillatory.

Example Consider the differential equation

$$
\left(t\left(y(t)+\frac{1}{2} y\left(\frac{t}{3}\right)\right)^{\prime \prime \prime}\right)^{\prime}+\frac{q_{0}}{t^{4}} y\left(\frac{t}{2}\right)=0,
$$


where $q_{0}>0$ is a constant. Note that $\gamma=\beta=1, r(t)=t, p_{0}(t)=1 / 2, q(t)=q_{0} / t^{4}, \delta(t)=t / 2$, and $\tau(t)=t / 3$. If we set $\pi(t)=t^{2}$, then

$$
\int_{t_{0}}^{\infty} \frac{1}{r(s)} \mathrm{d} s=\int_{t_{0}}^{\infty} \frac{1}{s} \mathrm{~d} s=\infty
$$

and

$$
B_{2}(t)=\pi(t) q(t)\left(1-p_{0}\right)^{\beta} M^{\beta-\gamma} \delta(t)=\frac{q_{0}}{4 t} .
$$

Thus we get

$$
\begin{aligned}
& \limsup _{t \rightarrow \infty} \frac{1}{t^{n}} \int_{t_{0}}^{t}(t-s)^{n}\left(B_{2}(t)-\frac{r(s)}{(\gamma+1)^{\gamma+1}} \frac{\left(\pi^{\prime}(s)\right)^{\gamma+1}}{\left(\varepsilon \pi(s) \delta^{2}(t) \zeta \delta^{\prime}(s)\right)^{\gamma}}\right) \mathrm{d} s \\
& \limsup _{t \rightarrow \infty} \frac{1}{t^{2}} \int_{t_{0}}^{t}(t-s)^{2} \frac{1}{s}\left(\frac{q_{0}}{4}-8\right) \mathrm{d} s=\infty .
\end{aligned}
$$

Therefore by Theorem 4.1 all solutions of (49) are oscillatory if $q_{0}>32$.

Remark 5.1 We can easily see that the results obtained in [32,33] cannot be applied to (36), so our results are new.

Remark 5.2 We can generalize our results by studying the equation

$$
\left(r(t)\left(z^{\prime \prime \prime}(t)\right)^{\gamma}\right)^{\prime}+\sum_{i=1}^{j} q_{i}(t) y^{\beta}\left(\delta_{i}(t)\right)=0, \quad t \geq t_{0}, j \geq 1 .
$$

For this, we leave the results to interested researchers.

Remark 5.3 For interested researchers, there is a good problem of finding new results for (1) where

$$
z(t):=y(t)-p(t) y(\tau(t))
$$

\section{Conclusions}

The aim of this paper was to provide a study of asymptotic nature for a class of fourthorder neutral delay differential equations. We used a Riccati substitution and the integral averaging technique to ensure that every solution of the studied equation is oscillatory. The results presented complement some of the known results reported in the literature.

A further extension of this paper is using our results to study a class of systems of higherorder neutral differential equations, including those of fractional order. Some research in this area is in progress.

\section{Acknowledgements}

The author express his debt of gratitude to the editors and the anonymous referee for accurate reading of the manuscript and beneficial comments. 
Availability of data and materials

Please contact author for data requests.

\section{Competing interests}

The author declares that he has no competing interests.

\section{Authors' contributions}

The author declares that he has read and approved the final manuscript.

\section{Publisher's Note}

Springer Nature remains neutral with regard to jurisdictional claims in published maps and institutional affiliations.

Received: 20 February 2020 Accepted: 27 April 2020 Published online: 07 May 2020

\section{References}

1. Agarwal, R., Grace, S., O'Regan, D.: Oscillation Theory for Difference and Functional Differential Equations. Kluwer Academic, Dordrecht (2000)

2. Agarwal, R.P., Bohner, M., Li, T., Zhang, C.: A new approach in the study of oscillatory behavior of even-order neutral delay differential equations. Appl. Math. Comput. 225, 787-794 (2013)

3. Baculikova, B., Dzurina, J., Li, T.: Oscillation results for even-order quasi linear neutral functional differential equations Electron. J. Differ. Equ. 2011, Article ID 143 (2011)

4. Bazighifan, O., Dassios, I.: On the asymptotic behavior of advanced differential equations with a non-canonical operator. Appl. Sci. 10, Article ID 3130 (2020)

5. Bazighifan, O., Elabbasy, E.M., Moaaz, O.: Oscillation of higher-order differential equations with distributed delay. J. Inequal. Appl. 2019, Article ID 55 (2019)

6. Chatzarakis, G.E., Elabbasy, E.M., Bazighifan, O.: An oscillation criterion in 4th-order neutral differential equations with a continuously distributed delay. Adv. Differ. Equ. 2019, Article ID 336 (2019)

7. Bazighifan, O., Cesarano, C.: A Philos-type oscillation criteria for fourth-order neutral differential equations. Symmetry 12, Article ID 379 (2020)

8. Bazighifan, O., Abdeljawad, T.: Improved approach for studying oscillatory properties of fourth-order advanced differential equations with $p$-Laplacian like operator. Mathematics 8, Article ID 656 (2020)

9. El-Nabulsi, R.A., Moaaz, O., Bazighifan, O.: New results for oscillatory behavior of fourth-order differential equations. Symmetry 12, Article ID 136 (2020)

10. Kiguradze, I.T., Chanturiya, T.A.: Asymptotic Properties of Solutions of Nonautonomous Ordinary Differential Equations. Kluwer Academic, Dordrecht (1993)

11. Ladde, G.S., Lakshmikantham, V., Zhang, B.: Oscillation Theory of Differential Equations with Deviating Arguments. Marcel Dekker, New York (1987)

12. Graef, J.R., Grace, S.R., Tunc, E.: Oscillatory behavior of even-order nonlinear differential equations with a sublinear neutral term. Opusc. Math. 39, 39-47 (2019)

13. Li, T., Han, Z., Zhao, P., Sun, S.: Oscillation of even-order neutral delay differential equations. Adv. Differ. Equ. 2010, Article ID 184180 (2010)

14. Moaaz, O.: New criteria for oscillation of nonlinear neutral differential equations. Adv. Differ. Equ. 2019, Article ID 484 (2019)

15. Moaaz, O., Elabbasy, E.M., Bazighifan, O.: On the asymptotic behavior of fourth-order functional differential equations. Adv. Differ. Equ. 2017, Article ID 261 (2017)

16. Moaaz, O., Elabbasy, E.M., Muhib, A.: Oscillation criteria for even-order neutral differential equations with distributed deviating arguments. Adv. Differ. Equ. 2019, Article ID 297 (2019)

17. Bazighifan, O., Ruggieri, M., Scapellato, A.: An improved criterion for the oscillation of fourth-order differential equations. Mathematics 8, Article ID 610 (2020)

18. Bazighifan, O., Postolache, M.: An improved conditions for oscillation of functional nonlinear differential equations. Mathematics 8, Article ID 552 (2020)

19. Bazighifan, O:: An approach for studying asymptotic properties of solutions of neutral differential equations. Symmetry 12, Article ID 555 (2020)

20. Bohner, M., Grace, S.R., Sager, I., Tunc, E.: Oscillation of third-order nonlinear damped delay differential equations. Appl. Math. Comput. 278, 21-32 (2016)

21. Graef, J., Grace, S., Tunc, E.: Oscillation criteria for even-order differential equations with unbounded neutral coefficients and distributed deviating arguments. Funct. Differ. Equ. 25, 143-153 (2018)

22. Graef, J.R., Grace, S.R., Tunc, E.: Oscillation of even-order advanced functional differential equations. Publ. Math. (Debr.) 93, 445-455 (2018)

23. Graef, J.R., Tunc, E.: Oscillation of fourth-order nonlinear dynamic equations on time scales. Panam. Math. J. 25, 16-34 (2015)

24. Dzurina, J., Grace, S.R., Jadlovska, I., Li, T.: Oscillation criteria for second-order Emden-Fowler delay differential equations with a sublinear neutral term. Math. Nachr. 293, 910-922 (2020). https://doi.org/10.1002/mana.201800196

25. Li, T., Rogovchenko, Yu.V.: On the asymptotic behavior of solutions to a class of third-order nonlinear neutral differential equations. Appl. Math. Lett. 105, Article ID 106293 (2020)

26. Li, T., Rogovchenko, Yu.V.: Oscillation criteria for second-order superlinear Emden-Fowler neutral differential equations. Monatshefte Math. 184(3), 489-500 (2017)

27. Chatzarakis, G.E., Grace, S.R., Jadlovska, I., Li, T., Tunc, E.: Oscillation criteria for third-order Emden-Fowler differential equations with unbounded neutral coefficients. Complexity 2019, Article ID 5691758 (2019)

28. Zhang, C., Agarwal, R.P., Li, T.: Oscillation and asymptotic behavior of higher-order delay differential equations with p-Laplacian like operators. J. Math. Anal. Appl. 409(2), 1093-1106 (2014) 
29. Li, T., Rogovchenko, Yu.V.: Asymptotic behavior of higher-order quasilinear neutral differential equations. Abstr. Appl. Anal. 2014, Article ID 395368 (2014)

30. Li, T., Rogovchenko, Yu.V.: Oscillation criteria for even-order neutral differential equations. Appl. Math. Lett. 61, 35-41 (2016)

31. Zhang, Q., Yan, J., Gao, L.: Oscillation behavior of even-order nonlinear neutral differential equations with variable coefficients. Comput. Math. Appl. 59, 426-430 (2010)

32. Xing, G., Li, T., Zhang, C.: Oscillation of higher-order quasi-linear neutral differential equations. Adv. Differ. Equ. 2011, Article ID 45 (2011)

33. Moaaz, O., Awrejcewicz, J., Bazighifan, O.: A new approach in the study of oscillation criteria of even-order neutral differential equations. Mathematics 12, Article ID 197 (2020)

34. Agarwal, R.P., Zhang, Ch., Li, T.: Some remarks on oscillation of second order neutral differential equations. Appl. Math Comput. 274, 178-181 (2016)

35. Philos, Ch.: On the existence of nonoscillatory solutions tending to zero at $\infty$ for differential equations with positive delays. Arch. Math. 36, 168-178 (1981)

Submit your manuscript to a SpringerOpen ${ }^{\circ}$ journal and benefit from:

- Convenient online submission

- Rigorous peer review

- Open access: articles freely available online

- High visibility within the field

- Retaining the copyright to your article

Submit your next manuscript at $\boldsymbol{\nabla}$ springeropen.com 